\title{
Awareness of Janani Suraksha Yojana Among Economically Backward Section in Rural Punjab
}

\author{
V. Pandey* and S. Kaur \\ Dept. of Home Science Extension and Communication Management, Punjab Agricultural University, \\ Ludhiana, Punjab (141 004), India
}

\section{Article History}

Manuscript No. AR1650a

Received in $6^{\text {th }}$ August, 2016

Received in revised form $25^{\text {th }}$ September, 2016

Accepted in final form $4^{\text {th }}$ October, 2016

\section{Correspondence to}

*E-mail: vinitapandey890@gmail.com

\section{Keywords}

Awareness, JSY, beneficiaries, rural mother, anganwadi workers

\begin{abstract}
The present study was conducted in Punjab state to assess the awareness of beneficiaries about Janani Suraksha Yojana (JSY). All the three socio-cultural zones of Punjab i.e. Majha, Malwa and Doaba were selected. A total of eleven districts i.e. seven from Malwa, two from Majha and two from Doaba were selected through proportionate random sampling. From each selected district two blocks were selected through purposive sampling. Hence, a total of 22 blocks were selected. From each block, one village was selected randomly. A list of beneficiaries in the age group of 20-35 years was prepared with the help of anganwadi workers and ASHA workers for each selected village. Twelve mothers were selected randomly from the prepared list. Thus, 264 beneficiaries comprised the sample for this purpose. A self-structured interview schedule was prepared to collect the data from the beneficiaries. Results revealed that most of the rural mothers were in the age group between 26-30 years and 30.0\% of them were educated up to middle level. Majority of the rural mothers were housewives and belonged to scheduled caste families. Rural mothers were fully aware about the specific aspects of JSY i.e. free transportation facilities and cash assistance for pregnant women. The results of the study also indicated that family income and organizational membership were significantly associated with level of awareness of the beneficiaries.
\end{abstract}

\section{Introduction}

Women who were the most dormant segment of Indian population have now become active participants in all walks of life. Now, women are becoming not only a significant unit of the society but also influencing the course of social change in society. But in rural India, the condition of mothers and children is alarming. They are a vulnerable or special-risk group and their risk is connected with child-bearing and care of infant during postpartum period.

The average female life expectancy in India is low compared to many countries, but it has shown gradual improvement over the years. In many families, especially rural ones, the girls and women face nutritional discrimination within the family, and are anemic and malnourished. Research into women's status in society has found that the contribution of Indian women to families is often overlooked. Instead, they are often regarded as economic burden and this view is common in rural areas of the northern belt. There is a strong preference for sons in India because they are expected to care for ageing parents. Indian women have low levels of both education and formal labour-force participation (Saha and Saha, 2010).
India accounts for the maximum number of maternal deaths in the World. $17.0 \%$ or nearly 50,000 of the 2.89 lakh women died as a result of complications due to pregnancy or childbearing in 2013 (Barnagarwala, 2014). Major factor for this high Maternal Mortality Rate (MMR) is lack of scientific child delivery practices. Instead child delivery is performed by local untrained Dais or by locally available elderly women of household (Status of Women in India, 2001). Only very small proportion of births in the country is supervised by health professionals. Most women deliver with help from women in the family who often lack skills and resources to save the mother's life if it is in danger (Nautiyal and Dabral, 2012). A large number of women in India suffer from gynecological problems. The average Indian woman bears her first child before 22 years of age, and has little control over her own fertility and reproductive health.

The maternal health issues continue to be at the forefront of global and national health policies in the last few years. Planning process focuses on reduction of maternal and childhood mortality (Mishra, 2007). India has $30 \mathrm{~m}$ pregnancies year $^{-1}$ which result in $27 \mathrm{~m}$ deliveries. Out of these $16 \mathrm{~m}$ $(60.0 \%)$ are home deliveries (NRHM newsletter, 2008). 
Around 77,000 maternal deaths occur every year because of various complications like haemorrhage, sepsis, abortion, obstructed labour etc. The vision for the XII five year plan is to ensure improving the position and condition of women by addressing structural and institutional barriers as well as strengthening gender mainstreaming. To improve the condition of mothers, a social assistance program was specifically designed for empowering poor households to avail preventive health services (Doetinchem et al., 2008). Therefore, a wellknown scheme Janani Suraksha Yojana (JSY) was launched in April, 2005 under the umbrella of National Rural Health Mission (NRHM) of India (Ministry of health and family welfare, 2006 and It is $100 \%$ centrally sponsored scheme aimed to reduce MMR by promoting institutional deliveries. This scheme has been modified from earlier National Maternity Benefit Scheme (NMBS). In NMBS, the benefits were limited to two live births, but under the revised scheme this restriction was removed. Also, the benefits of the scheme were extended to all BPL (Below Poverty Line) women.

The primary components of JSY include early registration, micro-birth planning, referral transport (home to health institution), post delivery visit and reporting, family planning and counseling. It is a demand driven intervention for promoting institutional delivery. It identifies Accredited Social Health Activist (ASHA) as an effective link between the Government and poor pregnant women in ten low performing states, namely the eight EAG (Empowered Action Group) states, Assam, J\&K and the remaining north eastern states. In other eligible states and UTs, wherever AWW and TBAs or ASHA like activist has been engaged for this purpose, they can be associated with this Yojana for providing services. In view of the above mentioned facts, the present study on 'Awareness of JSY among economically backward section in rural Punjab' has been taken up with the following objectives.

(a) To find out the extent of awareness regarding different aspects of JSY among beneficiaries.

(b) To study the level of awareness of beneficiaries about Janani Suraksha Yojana.

(c) To analyze the relationship between personal and socioeconomic characteristic and their level of awareness.

\section{Materials and Methods}

\subsection{Locale of the study}

The present study was conducted in Punjab State. The state of Punjab comprised of 22 Districts and three socio-cultural zones. All the three socio-cultural zones of Punjab i.e. Majha, Malwa and Doaba were selected for this study. The study was conducted from Jan. 2015 to Dec. 2015.

\subsection{Selection of districts}

Probability proportionate random sampling technique was used for selection of districts from each zone. There are fourteen districts in Malwa, four in Majha and four in Doaba region. Therefore, a total of eleven districts i.e. seven from Malwa, two from Majha and two from Doaba were covered under the study. Faridkot, Bathinda, Ludhiana, Mansa, Fatehgarh Sahib, Rupnagar and Sangrur from Malwa region, Gurdaspur and Tarn Taran from Majha region and Hoshiarpur and Kapurthala from Doaba were selected.

\subsection{Selection of blocks and villages}

From each selected district two blocks were selected through purposive sampling. It was ensured that one selected block was near the city while another was far from city to capture the data variations due the remoteness. Hence, a total of 22 blocks were selected. From each block one village was selected randomly. Hence, a total of 22 villages were selected for the study.

\subsection{Selection of beneficiaries}

Mothers in the age group of 20-35 years were considered beneficiaries for the purpose of study therefore a list of mothers in the age group of 20-35 years was prepared with the help of Aganwadi Workers (AWW) and Accredited Social Health Activist (ASHA) for each selected village. Twelve mothers were selected purposively from the prepared list. Thus, 264 beneficiaries comprised the sample for this purpose.

\subsection{Measurement of variables}

The variables for the study were selected based upon the review of literature and guidance of the experts. Age, education, occupation, family size, family type and family income, media exposure etc. were considered as a independent variables of the study while extent of awareness of the beneficiaries was the dependent variable of the study. A self-structured interview schedule was prepared to collect the data from the beneficiaries. Keeping in mind the objectives of the study, the collected data was analysed by using frequency, percentage, $\chi^{2}$ and kruskal Wallis $\mathrm{H}$ test.

\section{Results and Discussion}

\subsection{Personal and socio-economic characteristics}

The personal and socio-economic characteristics of the beneficiaries i.e. rural women and their families have been discussed under this category. In this study beneficiaries are the selected rural mothers. Profile of the respondents has been collected with respect of personal and socio-economic variables of age, caste, educational qualification, family type, family size, respondents' income and family income. The data pertaining to the socio-economic features of the respondents has been presented in (Table 1). A large proportion of the 


\begin{tabular}{|c|c|c|c|c|c|c|c|c|c|}
\hline \multirow[t]{3}{*}{ Beneficiaries' profile } & \multirow[t]{3}{*}{ Category } & \multicolumn{8}{|c|}{ Beneficiaries } \\
\hline & & \multicolumn{2}{|c|}{ Malwa $\left(\mathrm{n}_{1}=168\right)$} & \multicolumn{2}{|c|}{ Majha $\left(\mathrm{n}_{2}=48\right)$} & \multicolumn{2}{|c|}{$\operatorname{Doaba}\left(\mathrm{n}_{3}=48\right)$} & \multicolumn{2}{|c|}{ Overall } \\
\hline & & $\mathrm{F}$ & $\%$ & $\mathrm{f}$ & $\%$ & $\mathrm{f}$ & $\%$ & $\mathrm{f}$ & $\%$ \\
\hline \multicolumn{10}{|l|}{ Personal profile } \\
\hline \multirow[t]{3}{*}{ Age (years) } & $20-25$ & 60 & 35.71 & 6 & 12.50 & 17 & 35.42 & 83 & 31.44 \\
\hline & $26-30$ & 105 & 62.50 & 42 & 87.50 & 29 & 60.42 & 176 & 66.67 \\
\hline & $31-35$ & 3 & 1.79 & - & - & 2 & 4.17 & 5 & 1.89 \\
\hline \multirow[t]{7}{*}{ Education } & Illiterate & 1 & 0.60 & - & - & 1 & 2.09 & 2 & 0.76 \\
\hline & $\begin{array}{l}\text { Can read and } \\
\text { write }\end{array}$ & 16 & 9.52 & 3 & 6.25 & 4 & 8.33 & 23 & 8.71 \\
\hline & Primary & 50 & 29.76 & 14 & 29.17 & 17 & 35.42 & 81 & 30.68 \\
\hline & Middle & 36 & 21.43 & 11 & 22.92 & 5 & 10.42 & 52 & 19.70 \\
\hline & Matric & 40 & 23.81 & 10 & 20.83 & 6 & 12.50 & 56 & 21.21 \\
\hline & $10+2$ & 25 & 14.88 & 10 & 20.83 & 13 & 27.08 & 48 & 18.18 \\
\hline & Graduate & - & - & - & - & 2 & 4.17 & 2 & 0.76 \\
\hline \multirow[t]{4}{*}{ Caste } & General & - & - & - & - & - & - & - & - \\
\hline & Scheduled caste & 153 & 91.07 & 45 & 93.75 & 43 & 89.58 & 241 & 91.29 \\
\hline & Scheduled tribes & 1 & 0.60 & - & - & 1 & 2.08 & 2 & 0.76 \\
\hline & Backward classes & 14 & 8.33 & 3 & 6.25 & 4 & 8.33 & 21 & 7.95 \\
\hline \multirow[t]{3}{*}{ Religion } & Hindu & 48 & 28.57 & 20 & 41.67 & 30 & 62.50 & 98 & 37.12 \\
\hline & Muslim & - & - & - & - & - & - & - & - \\
\hline & Sikh & 120 & 71.43 & 28 & 58.34 & 18 & 37.50 & 166 & 62.88 \\
\hline \multirow[t]{5}{*}{ Occupation } & Business & - & - & - & - & - & - & - & - \\
\hline & Farming & - & - & - & - & - & - & - & - \\
\hline & Service & - & - & - & - & - & - & - & - \\
\hline & House wife & 158 & 94.05 & 48 & 100.00 & 44 & 91.67 & 250 & 94.70 \\
\hline & Labour & 10 & 5.95 & - & - & 4 & 8.33 & 14 & 5.30 \\
\hline \multirow{6}{*}{$\begin{array}{l}\text { Beneficiaries } \\
\left.\text { income (₹ annum }{ }^{-1}\right)\end{array}$} & No income & 158 & 94.04 & 48 & 100.00 & 45 & 93.75 & 251 & 95.08 \\
\hline & Up to 10000 & 1 & 0.60 & - & - & 2 & 4.17 & 4 & 1.51 \\
\hline & $10001-20000$ & - & - & - & - & - & - & - & - \\
\hline & $20001-30000$ & 1 & 0.59 & - & - & - & - & 1 & 0.38 \\
\hline & $30001-40000$ & - & - & - & - & 1 & 2.08 & 1 & 0.38 \\
\hline & $>40000$ & 7 & 4.16 & - & - & - & 0.00 & 7 & 2.65 \\
\hline \multirow[t]{2}{*}{ Family type } & Nuclear & 76 & 45.24 & 22 & 45.83 & 16 & 33.33 & 114 & 43.18 \\
\hline & Joint & 92 & 54.76 & 26 & 54.17 & 32 & 66.67 & 150 & 56.82 \\
\hline \multirow[t]{3}{*}{ Family size } & Up to 4 (small) & 57 & 33.93 & 16 & 33.33 & 9 & 18.75 & 82 & 31.06 \\
\hline & 5-8 (medium) & 105 & 62.50 & 31 & 64.58 & 38 & 79.17 & 174 & 65.91 \\
\hline & $>8$ (high) & 6 & 3.57 & 1 & 2.09 & 1 & 2.08 & 8 & 3.03 \\
\hline \multirow{5}{*}{$\begin{array}{l}\text { Family income } \\
\left(₹ \text { annum }{ }^{-1}\right)\end{array}$} & Up to 50000 & 10 & 5.95 & - & - & - & - & 10 & 3.79 \\
\hline & 50001-100000 & 107 & 63.69 & 27 & 56.25 & 42 & 87.50 & 176 & 66.67 \\
\hline & $100001-150000$ & 50 & 29.76 & 21 & 43.75 & 6 & 12.50 & 77 & 29.17 \\
\hline & $150001-200000$ & - & - & - & - & - & - & - & - \\
\hline & 200001-300000 & 1 & 0.60 & - & - & - & - & 1 & 0.38 \\
\hline
\end{tabular}




\begin{tabular}{|c|c|c|c|c|c|c|c|c|c|}
\hline \multirow[t]{3}{*}{ Beneficiaries' profile } & \multirow[t]{3}{*}{ Category } & \multicolumn{8}{|c|}{ Beneficiaries } \\
\hline & & \multicolumn{2}{|c|}{ Malwa $\left(\mathrm{n}_{1}=168\right)$} & \multicolumn{2}{|c|}{ Majha $\left(\mathrm{n}_{2}=48\right)$} & \multicolumn{2}{|c|}{ Doaba $\left(\mathrm{n}_{3}=48\right)$} & \multicolumn{2}{|c|}{ Overall } \\
\hline & & $\mathrm{F}$ & $\%$ & $\mathrm{f}$ & $\%$ & $\mathrm{f}$ & $\%$ & $\mathrm{f}$ & $\%$ \\
\hline \multicolumn{10}{|l|}{ Social profile } \\
\hline \multirow[t]{3}{*}{ Mass media exposure } & Low $(0-3)$ & 164 & 97.6 & 45 & 93.8 & 48 & 100.0 & 257 & 97.3 \\
\hline & Medium (4-7) & 4 & 2.4 & 3 & 6.2 & - & - & 7 & 2.7 \\
\hline & $\operatorname{High}(8-12)$ & - & - & - & - & - & - & - & - \\
\hline \multirow{4}{*}{$\begin{array}{l}\text { Organizational } \\
\text { membership }\end{array}$} & No membership & 133 & 79.17 & 34 & 70.83 & 44 & 91.67 & 211 & 79.92 \\
\hline & Panchayat & - & - & - & - & - & - & - & - \\
\hline & Mahila Mandal & - & - & - & - & - & - & - & - \\
\hline & Self-Help group & 35 & 20.83 & 14 & 29.17 & 4 & 8.33 & 53 & 20.08 \\
\hline \multirow{3}{*}{$\begin{array}{l}\text { Sources of information } \\
\text { about programme }\end{array}$} & Panchayat & 32 & 19.04 & 8 & 16.67 & 6 & 12.50 & 46 & 17.42 \\
\hline & $\begin{array}{l}\text { Relatives/neighbour/ } \\
\text { friend }\end{array}$ & 40 & 23.82 & 20 & 41.67 & 23 & 47.92 & 83 & 31.44 \\
\hline & NRHM functionaries & 96 & 57.14 & 20 & 41.67 & 19 & 39.58 & 135 & 51.14 \\
\hline
\end{tabular}

respondents i.e. $66.67 \%$ were in the age group of $26-30$ years followed by $31.44 \%$ in the age range of $20-25$ years and only $1.89 \%$ within $31-35$ years. Trend was similar in all three sociocultural zones. The reason of higher percentage of respondents under the age category of 26-30 years may be conferred to the fact that women in this age group are reproductively active having 1 or 2 children which is the basic requirement of Janani Suraksha Yojana scheme for cash assistance. The results of the studies conducted by Ray (2014) also concluded that Janani Suraksha Yojana respondents in majority were in 26-35 years of age group. As far as the educational qualification of the respondents was concerned, $30.68 \%$ of the respondents were educated up to primary level while $21.2 \%$ had education up to matric closely followed by middle level $(19.70 \%)$ and less than $1 \%$ of the respondents were illiterate and graduate. In all the zones, the highest portion of the respondents was educated up to primary level. Kaur et al. (2015) found that $30.4 \%$ of the JSY beneficiaries were educated below matric. These results clearly reveal the education scenario of the rural Punjab.

Majority of the respondents (91.29\%) belonged to scheduled caste category and only $0.76 \%$ to other backward class category. No respondents belonged to general category. Similar pattern was observed in all three zones. The reason for higher proportion of scheduled caste families in this study may be due to the cash assistance facilities of JSY scheme in which cash assistance is provided to the BPL/SC/OBC category of women. The results of the study are supported by Singh and Tamulee (2012). More than half of the respondents were Sikh and only $37.12 \%$ were Hindu. The zone wise analysis also revealed that highest percentage (62.8\%) belonged to Sikh religion. Doaba had the highest per cent of Hindu (62.5\%) as compared to Majha (41.6\%) and Malwa (28.5\%). The Malwa region had the highest percentage (71.4\%) of Sikh followed by Majha (58.34\%) and Doaba (37.5\%). Kaur et al. (2015) conducted a study on utilization of JSY scheme, among beneficiaries in a rural area of Punjab and the findings of the study indicated that majority (67.0\%) of the beneficiaries were Sikh and only one third of the beneficiaries were Hindu The reason of the high proportion of Sikh respondents was the locale of study as Punjab which is a Sikh dominant state.

Occupation of the respondents was classified into business, farming, service and housewife. The data regarding the occupation of the respondents showed that a large majority $(94.70 \%)$ was housewives and only $5.30 \%$ were labour class. Zone wise comparison showed that housewives were in majority in Majha (100\%) while Malwa and Doaba had $94.5 \%$ and $91.67 \%$ housewives respectively in the sample. The data shows that $8.33 \%$ respondents in Doaba were labourer as compared to $5.95 \%$ in Malwa. The results of the study are in line with the results given by Sharma et al., 2012. Overall a large majority of respondents $(95.4 \%)$ had no income and nearly $4.0 \%$ of the beneficiaries had income up to 10000 thousands annum ${ }^{-1}$. The trend was similar across zones. These results are due to the sample of the study, as majority of the housewives did not have independent income. More than half of the respondents were from joint families while $43.18 \%$ of them were from nuclear families. The similar trend was observed in all the three socio-cultural zones. The results of the study were supported by Chatterjee et al., 2015. Majority $(65.91 \%)$ of the respondents had a medium family size i.e. 
5-8 members followed by $31.06 \%$ who had $1-4$ members and only $3.41 \%$ had more than 8 members in their families. It clearly indicated that majority of the respondents belonged to a medium sized families. Similar trend was observed in all zones. Ade et al. (2014) reported that majority of women $(61.0 \%)$ had family size less than or equal to 5 . Most (65.91\%) of the beneficiaries' family income was 50.0 thousands to one lakh annum ${ }^{-1}$ and only $28.79 \%$ beneficiaries' family had one lakh to 1.5 lakh annum ${ }^{-1}$ family income. Trend was similar across regions.

As far as the media exposure of the respondents was concerned $97.3 \%$ of the respondents had low level of media exposure. Only $2.7 \%$ of the respondents used media to the medium level. All the three zones had majority of respondents in low level of media exposure. Majority (80.0\%) of the respondents had no membership. Zone wise analysis shows that nearly $30.0 \%$ of the respondents of Majha region had membership followed by Malwa (21.0\%).

Majority (51.14\%) of the respondents' source of information were National Rural Health Mission functionaries (ASHA/ ANM/AWW) while $31.44 \%$ respondents' source of information were friends/neighbours/relatives and remaining $17.42 \%$ respondents' source of information were panchayat members. Zone wise analysis depicted that majority of the beneficiaries of Malwa region mentioned that NRHM functionaries i.e. ANM, ASHA and AWW were the main sources of information about the JSY followed by relatives/neighbours/friends (23.82\%). Similar percentage $(42.47 \%)$ of the beneficiaries of Majha region reported that NRHM functionaries and relatives/ neighbour/friend were the main sources of information about JSY while half of the beneficiaries of Doaba region mentioned that main sources of information about Janani Suraksha Yojana were relatives/friends/neighbours followed by NRHM functionaries (39.58\%). Singh and Tamulee (2012) reported that majority $(72.0 \%)$ of the respondents' source of information were the neighbours and $18.4 \%$ had ASHA as their source, $6.2 \%$ as members of family and $2.7 \%$ came to know from the primary health care centre (PHCs) about JSY while Kaur et al. (2015) found that $45.0 \%$ of the beneficiaries had heard about JSY from health workers.

Hence it can be concluded that majority of the respondents were young with education up to middle level and belonged to scheduled caste category. The families were mostly medium size with 5-8 members but had low income level. The membership of organization and the use of media were found to below.

\subsection{Extent of awareness regarding different aspects of JSY}

This part deals with the awareness of the beneficiaries about different aspects of JSY i.e. Scheme objective, benefits to rural mothers, benefits to health functionaries and roles and responsibilities of rural mother and functionaries. The mean score of each aspect was calculated by assigning 2, 1 and 0 score to response categories i.e. fully aware, somewhat aware and not aware respectively. Level of awareness was also categorized into low, medium and high according to score range. The awareness related data has been discussed under different categories:

\subsubsection{Awareness regarding objective}

The data regarding objective of JSY has been given in Table 2 . It can be seen that beneficiaries were aware about its objective with mean value 0.95 . The zone wise analysis shows that beneficiaries of Malwa region were also fully aware about objective of JSY with mean value 1.03 followed by Doaba (mean 0.9) and Majha (mean 0.89) regions. Mandal et al. (2012) observed that $64.0 \%$ women eligible for benefit in West Bengal had heard the name of JSY. Similar results were also reported by Sharma et al. ( 2012).

\subsubsection{Awareness regarding benefits to beneficiaries}

The data in Table 2 indicated the awareness of beneficiaries regarding their benefits. The maximum awareness was found regarding 'free transportation facility' with mean value 2.0 and 'cash assistance delivery' with mean value 1.95 . The least awareness was found regarding 'functionaries support during post natal care' i.e. 1.16.

Zone wise analysis revealed that respondents of all the zones were fully aware of 'free transportation facility' (2.0) 'cash assistance for delivery (2.0)'. The reason for high awareness about their benefits may the financial need of the rural mothers and environment of poor families in cash assistance related schemes. The results of the study are in agreement with the study which was conducted by Sharma et al. (2012) who reported that (95.42\%) females in Dehradun were aware about the benefits under JSY.

\subsubsection{Awareness regarding benefits of functionaries}

The data as shown in Table 2 indicates that rural mothers were least aware about the functionaries' benefits (mean 0.48). The zone wise analysis revealed that least awareness was found in Majha region with mean 0.73 followed by Malwa (0.63) and Doaba (0.63). Illiteracy of the respondents was the main reason for not having proper awareness about benefits of functionaries under JSY. The results of the study are in disagreement with the study of Kaushik et al. (2010) who reported that $50.0 \%$ of the beneficiaries were aware about the payment which is given to functionaries to accompanying pregnant mothers under JSY.

3.2.4. Awareness regarding roles and responsibilities of beneficiaries

The data given in Table 2 indicated that maximum awareness 
Table 2: Mean score differences in awareness among beneficiaries about Janani Suraksha Yojana across socio-cultural zones of Punjab $(n=264)$

\begin{tabular}{|c|c|c|c|c|c|}
\hline \multirow{3}{*}{$\begin{array}{l}\text { Aspects } \\
\text { Dimensions of programme }\end{array}$} & \multicolumn{5}{|c|}{ Beneficiaries } \\
\hline & $\begin{array}{c}\text { Malwa } \\
\left(\mathrm{n}_{1}=168\right)\end{array}$ & $\begin{array}{l}\text { Majha } \\
\left(\mathrm{n}_{2}=48\right)\end{array}$ & $\begin{array}{c}\text { Doaba } \\
\left(\mathrm{n}_{3}=48\right)\end{array}$ & Overall & \multirow{2}{*}{$\begin{array}{c}\text { Kruskal } \\
\text { Wallis H } \\
\text { test }\end{array}$} \\
\hline & Mean & Mean & Mean & Mean & \\
\hline \multicolumn{6}{|l|}{ Objective } \\
\hline Promote institutional and safe delivery & 1.03 & 0.89 & 0.94 & 0.95 & $2.15^{\mathrm{NS}}$ \\
\hline \multicolumn{6}{|l|}{ Benefits for beneficiaries } \\
\hline Free transportation facility & 2.0 & 2.0 & 2.0 & 2.0 & NA \\
\hline Cash assistance for delivery & 1.92 & 2.0 & 2.0 & 1.95 & $4.10^{\mathrm{NS}}$ \\
\hline Functionaries support for post natal care & 1.13 & 1.19 & 1.27 & 1.16 & $0.83^{\mathrm{NS}}$ \\
\hline \multicolumn{6}{|l|}{ Benefits for functionaries } \\
\hline Incentives for beneficiaries help & 0.63 & 0.73 & 0.63 & 0.65 & $0.82^{\mathrm{NS}}$ \\
\hline \multicolumn{6}{|l|}{ Roles and responsibilities of the beneficiaries } \\
\hline Inform the health worker about pregnancy & 0.89 & 1.0 & 0.85 & 0.90 & $0.69^{\mathrm{NS}}$ \\
\hline Register name at the sub centre & 0.99 & 1.23 & 0.94 & 1.03 & $4.64^{\mathrm{NS}}$ \\
\hline Receive at least 3 ANC checkups & 0.96 & 1.04 & 1.13 & 1.0 & $3.98^{\mathrm{NS}}$ \\
\hline Maintain JSY documents & 1.18 & 1.31 & 1.33 & 1.23 & $3.46^{\mathrm{NS}}$ \\
\hline \multicolumn{6}{|l|}{ Roles and responsibilities of the functionaries } \\
\hline Identification of pregnant women & 0.74 & 0.69 & 0.71 & 0.73 & $0.31^{\mathrm{NS}}$ \\
\hline Assist pregnant woman to obtain necessary certifications & 0.88 & 0.96 & 1.08 & 0.93 & $3.36^{\mathrm{NS}}$ \\
\hline Help women in receiving at least three ANC checkups & 1.65 & 1.56 & 1.58 & 1.62 & $0.26^{\mathrm{NS}}$ \\
\hline Identification of a functional Government health centre & 1.46 & 1.25 & 1.25 & 1.38 & $3.98^{\mathrm{NS}}$ \\
\hline Counsel for institutional delivery & 0.70 & 0.67 & 0.73 & 0.70 & $0.11^{\mathrm{NS}}$ \\
\hline Escort beneficiary women to the pre-determined health center & 1.58 & 1.58 & 1.58 & 1.58 & $0.06^{\mathrm{NS}}$ \\
\hline Immunize newborn & 0.89 & 1.10 & 1.04 & 0.96 & $4.04^{\mathrm{NS}}$ \\
\hline Inform about birth or death of child to medical officer & 0.68 & 0.73 & 0.69 & 0.69 & $0.36^{\mathrm{NS}}$ \\
\hline Post natal visit & 1.45 & 1.46 & 1.48 & 1.45 & $0.24^{\mathrm{NS}}$ \\
\hline Counsel for initiation of breastfeeding & 1.33 & 1.54 & 1.42 & 1.39 & $2.67^{\mathrm{NS}}$ \\
\hline Name based tracking of missed and left out ANC cases & 0.02 & - & 0.02 & 0.02 & $0.92^{\mathrm{NS}}$ \\
\hline Kruskal Wallis H Test & $362.08^{* *}$ & $128.75^{* *}$ & $143.70^{* *}$ & & \\
\hline
\end{tabular}

Score range $(0-2),{ }^{* *}$ Significant at $(p=0.01)$ level of significance, \# NS-Non significant

was found for items i.e. 'Receive at least three antenatal checkups (ANC)' (1.70), 'register name at the sub centre' (1.62) and 'maintain proper documents' (1.45). Least awareness was found for item i.e. 'inform the health workers about pregnancy' (0.44). The reason of low awareness may be due to the cultural constraints which do not allow rural women to discuss these things with outsiders. The results of the study are in line with the study conducted by Pahwa and Sood (2013) in Mohali, Punjab among the 164 respondents and it was found that majority (50.0\%) were registered by ANM and only $46.0 \%$ got registered in $1^{\text {st }}$ trimester. More than $50.0 \%$ of the mothers received antenatal check-ups (ANC) services and $52.0 \%$ of them completed three ANC visits. Time of registration plays a very important role in evaluating the services from the supply side. The results of the study show that rural mothers are more conscious about their role and responsibilities under JSY.

3.2.5. Awareness regarding roles and responsibilities of functionaries

Roles and responsibilities of the health worker refer to work assigned to them by the government. It is clearly evident from Table 2 that the maximum awareness was shown for items such as 'help the women in receiving at least three antenatal checkups'(1.62), 'escort beneficiary women to the pre-determined health center' (1.58), 'post natal visit' (1.45), 'counsel for 
initiation of breast feeding' (1.39) and 'identification of a functional government health centre' (1.38) while the least awareness was shown for items i.e. 'Inform about birth or death of the child to medical officer' ( 0.69$)$, 'counsel for institutional delivery' (0.70) and 'identification of pregnant women' (0.73). The least awareness about above responsibilities of the functionaries may be the reason of illiteracy and lack of interest among beneficiaries.

Zone wise analysis revealed that rural mothers of all the regions were fully aware about 'help the women to receive three antenatal check-ups (ANC)', 'escort the beneficiary to the predetermined health centers', 'counsel for initiation of breast feeding', 'identification of functional Government hospital', 'postnatal visit'. Respondents of all zones were least aware about the items i.e. 'Identification of the pregnant women', 'counsel for institutional delivery', 'inform about the birth or death of the child to MO' and 'name based tracking of missed and left out ANC cases'.

Respondents of Doaba region were aware about the item such as 'assist the pregnant woman to obtain necessary certifications' with mean score 1.0 in comparison to Malwa (0.88) and Majha (0.96) region. Maximum respondents of Majha (1.10) and Doaba (1.04) region were fully aware about the item such as 'immunize newborn' while Malwa respondents were least aware about this (0.89). Thus, overall there is high level of awareness about Janani Suraksha Yojana but the differences among the zones were found to be statistically non-significant. Population council (2011) report mentioned that one-quarter of all women (24\%) had received the ASHA's help during pregnancy, with more rural than urban women reporting so ( $28 \%$ versus $9 \%$ ). The type of assistance typically provided by the ASHA included enabling women to get immunised $(19 \%)$, facilitating antenatal registration $(18 \%)$ and antenatal check-ups (16\%), and helping women to get iron and folic acid supplements (15\%). Beneficiaries were overall aware about the different provisions under JSY. It shows the positive sign of improvement of the scheme in the selected districts of Punjab.

The Kruskal Wallis $\mathrm{H}$ test values show that significant variations between the response regarding different aspects of the JSY at $(p \leq 0.01)$ level, signifying that the extent of awareness of beneficiaries was significantly different regarding different aspects of the JSY.

\subsection{Level of awareness of beneficiaries about Janani Suraksha Yojana}

Level of awareness of rural mothers about JSY is given in Table 3. Based upon the three variables of awareness it was found that overall awareness of majority $(72.3 \%)$ of the respondents regarding different aspects of the programme was to a medium level. One fourth of rural mothers were in the high category and very few i.e. 5.30\% were in the low category. Maximum number $(29.1 \%)$ of the respondents of Doaba region had higher level of awareness while very few i.e. $2.0 \%$ and $6.5 \%$ respondents of Majha and Malwa had low level of awareness about the programme respectively. Majority $(77.0 \%)$ of the respondents of Majha region were in the medium level category followed by Malwa (72.6\%) and Doaba (66.6\%).

The results of the study are in agreement with the findings of the study 'Concurrent assessment of JSY scheme in selected states of India', 2008 which reported the awareness level of $75.9 \%$ respondents regarding the scheme in Uttar Pradesh. The results of the study are in disagreement with the results of Ramniwas and Prabhu (2015) who found that majority $(51.0 \%)$ of the respondents had inadequate knowledge, (40.1\%) had moderately adequate knowledge and only 8.9\% had adequate knowledge about Janani Suraksha Yojana. Similar results reported by Panja et al. (2016). The reason of this difference may be the less involvement of the functionaries with the community people or may be the lack of knowledge among the functionaries about health scheme.

\subsection{Association between personal and socio-economic} characteristics of the beneficiaries and their level of awareness

The association of different characteristics of the beneficiaries and their family was studied and has been shown in Table 4. Comparing the level of awareness by different age group reveals that maximum beneficiaries $(69.84 \%)$ were in the age category of 26-30 years and had high level of awareness regarding JSY. The remaining $63.64 \%$ and $65.79 \%$ in $26-30$ years of age range were also in low and medium level category respectively. The chi square value 0.69 is less than table value indicating no association between age and level of awareness of beneficiaries.

Similar results were found in case of education, caste, religion, occupation, family type, family size, respondent's income and mass media exposure. The significant association was found

Table 3: Distribution of beneficiaries according to their level of awareness regarding Janani Suraksha Yojana across sociocultural zones of Punjab $n=264$

\begin{tabular}{|c|c|c|c|c|c|c|c|c|}
\hline \multirow{3}{*}{$\begin{array}{l}\text { Level of } \\
\text { aware- } \\
\text { ness }\end{array}$} & \multicolumn{8}{|c|}{ Beneficiaries } \\
\hline & \multicolumn{2}{|c|}{$\begin{array}{c}\text { Malwa } \\
\left(\mathrm{n}_{1}=168\right)\end{array}$} & \multicolumn{2}{|c|}{$\begin{array}{r}\text { Majha } \\
\left(\mathrm{n}_{2}=48\right)\end{array}$} & \multicolumn{2}{|c|}{$\begin{array}{l}\text { Daoba } \\
\left(\mathrm{n}_{3}=48\right)\end{array}$} & \multicolumn{2}{|c|}{ Overall } \\
\hline & $\mathrm{f}$ & $\%$ & $\mathrm{f}$ & $\%$ & $\mathrm{f}$ & $\%$ & $\mathrm{f}$ & $\%$ \\
\hline $\begin{array}{l}\text { Low } \\
(0-12)\end{array}$ & 11 & 6.55 & 1 & 2.09 & 2 & 4.17 & 14 & 5.30 \\
\hline $\begin{array}{l}\text { Medium } \\
(13-25)\end{array}$ & 122 & 72.62 & 37 & 77.08 & 32 & 66.67 & 191 & 72.35 \\
\hline $\begin{array}{l}\text { High } \\
(26-40)\end{array}$ & 35 & 20.83 & 10 & 20.83 & 14 & 29.17 & 59 & 22.35 \\
\hline
\end{tabular}




\begin{tabular}{|c|c|c|c|c|c|c|c|c|}
\hline \multirow{2}{*}{$\begin{array}{l}\text { Socio-personal } \\
\text { characteristics }\end{array}$} & \multicolumn{7}{|c|}{ Level of awareness } & \multirow[t]{2}{*}{$\chi^{2}$ value } \\
\hline & Low & $\%$ & Medium & $\%$ & High & $\%$ & Total & \\
\hline $20-25$ & 4 & 36.36 & 61 & 32.11 & 18 & 28.57 & 83 & $0.69^{\mathrm{NS}}$ \\
\hline $26-30$ & 7 & 63.64 & 125 & 65.79 & 44 & 69.84 & 176 & \\
\hline $31-35$ & 0 & 0.0 & 4 & 2.11 & 1 & 1.59 & 5 & \\
\hline \multicolumn{9}{|l|}{ Education } \\
\hline Illiterate & 0 & 0 & 1 & 0.51 & 1 & 1.75 & 2 & $12.62^{\mathrm{NS}}$ \\
\hline Can read and write & 1 & 8.33 & 20 & 10.26 & 2 & 3.51 & 23 & \\
\hline Primary & 6 & 50.0 & 59 & 30.26 & 16 & 28.07 & 81 & \\
\hline Middle & 3 & 25.0 & 39 & 20.0 & 10 & 17.54 & 52 & \\
\hline Matric & 2 & 16.67 & 36 & 18.46 & 18 & 31.58 & 56 & \\
\hline $10+2$ & 0 & 0.0 & 39 & 20.0 & 9 & 15.79 & 48 & \\
\hline Graduate & 0 & 0.0 & 1 & 0.51 & 1 & 1.75 & 2 & \\
\hline \multicolumn{9}{|l|}{ Caste } \\
\hline General & 0 & 0.0 & 0 & 0.0 & 0 & 0.0 & 0 & $4.51^{\mathrm{NS}}$ \\
\hline Scheduled castes & 14 & 100.0 & 172 & 89.12 & 55 & 96.49 & 241 & \\
\hline Scheduled tribes & 0 & 0.0 & 2 & 1.04 & 0 & 0.0 & 2 & \\
\hline Backward classes & 0 & 0.0 & 19 & 9.84 & 2 & 3.51 & 21 & \\
\hline \multicolumn{9}{|l|}{ Religion } \\
\hline Hindu & 1 & 9.09 & 74 & 38.54 & 23 & 37.70 & 98 & $3.87^{\mathrm{NS}}$ \\
\hline Muslim & 0 & 0.0 & 0 & 0.0 & 0 & 0.0 & 0 & \\
\hline Sikh & 10 & 90.90 & 118 & 61.46 & 38 & 62.29 & 166 & \\
\hline \multicolumn{9}{|l|}{ Occupation } \\
\hline Business & 0 & 0.0 & 0 & 0.0 & 0 & 0.0 & 0 & $0.42^{\mathrm{NS}}$ \\
\hline Farming & 0 & 0.0 & 0 & 0.0 & 0 & 0.0 & 0 & \\
\hline Service & 0 & 0.0 & 0 & 0.0 & 0 & 0.0 & 0 & \\
\hline House wife & 10 & 90.90 & 193 & 95.07 & 47 & 94 & 250 & \\
\hline Labour & 1 & 9.09 & 10 & 4.93 & 3 & 6 & 14 & \\
\hline \multicolumn{9}{|l|}{ Type of family } \\
\hline Nuclear & 4 & 36.36 & 81 & 41.75 & 29 & 49.15 & 114 & $1.22^{\mathrm{NS}}$ \\
\hline Joint & 7 & 63.64 & 113 & 58.25 & 30 & 50.85 & 150 & \\
\hline \multicolumn{9}{|l|}{ Family size } \\
\hline Up to 4 (small) & 2 & 16.67 & 55 & 28.21 & 25 & 43.10 & 82 & $6.5^{\mathrm{NS}}$ \\
\hline 5-8 (medium) & 10 & 83.33 & 133 & 68.21 & 31 & 53.45 & 174 & \\
\hline$>8$ (high) & 0 & 0.0 & 7 & 3.59 & 2 & 3.45 & 9 & \\
\hline \multicolumn{9}{|c|}{ Respondent's income (₹ annum ${ }^{-1}$ ) } \\
\hline No income & 10 & 90.91 & 181 & 94.76 & 61 & 98.39 & 252 & $7.3^{\mathrm{NS}}$ \\
\hline Up to 10000 & 1 & 9.09 & 9 & 4.71 & 0 & 0.0 & 10 & \\
\hline $10001-20000$ & 0 & 0.0 & 0 & 0.0 & 0 & 0.0 & 0 & \\
\hline 20001-30000 & 0 & 0.0 & 0 & 0.0 & 0 & 0.0 & 0 & \\
\hline $30001-40000$ & 0 & 0.0 & 0 & 0.0 & 1 & 1.61 & 1 & \\
\hline$>40000$ & 0 & 0.0 & 1 & 0.52 & 0 & 0.0 & 1 & \\
\hline
\end{tabular}




\begin{tabular}{|c|c|c|c|c|c|c|c|c|}
\hline \multirow{2}{*}{$\begin{array}{l}\begin{array}{l}\text { Socio-personal } \\
\text { characteristics }\end{array} \\
\text { Age (years) } \\
\end{array}$} & \multicolumn{7}{|c|}{ Level of awareness } & \multirow{2}{*}{$\chi^{2}$ value } \\
\hline & Low & $\%$ & Medium & $\%$ & High & $\%$ & Total & \\
\hline \multicolumn{9}{|c|}{ Family income (₹ annum $\left.{ }^{-1}\right)$} \\
\hline Up to 50000 & 1 & 14.29 & 8 & 3.65 & 1 & 2.63 & 10 & $19.5^{* *}$ \\
\hline $50001-100000$ & 2 & 28.57 & 154 & 70.32 & 18 & 47.37 & 174 & \\
\hline $100001-150000$ & 4 & 57.14 & 55 & 25.11 & 17 & 44.74 & 76 & \\
\hline 150001-200000 & 0 & 0.0 & 0 & 0.0 & 0 & 0.0 & 0 & \\
\hline 200001-300000 & 0 & 0.0 & 1 & 0.46 & 0 & 0.0 & 1 & \\
\hline Above 300000 & 0 & 0.0 & 1 & 0.46 & 2 & 5.26 & 3 & \\
\hline \multicolumn{9}{|c|}{ Mass media exposure } \\
\hline Low $(0-4)$ & 9 & 90.0 & 188 & 98.43 & 60 & 95.24 & 257 & $4.0 \mathrm{NS}$ \\
\hline Medium (4-8) & 1 & 10.0 & 3 & 1.57 & 3 & 4.76 & 7 & \\
\hline High (8-12) & 0 & 0.0 & 0 & 0.0 & 0 & 0.0 & 0 & \\
\hline \multicolumn{9}{|c|}{ Organizational membership } \\
\hline No membership & 9 & 75.0 & 150 & 78.53 & 52 & 85.25 & 139 & $6.33^{* *}$ \\
\hline Panchayat & 0 & 0.0 & 0 & 0.0 & 0 & 0.0 & 0 & \\
\hline Mahila Mandal & 0 & 0.0 & 0 & 0.0 & 0 & 0.0 & 0 & \\
\hline Self-Help Group & 3 & 25.0 & 41 & 21.47 & 9 & 14.75 & 53 & \\
\hline
\end{tabular}

Significant at $(p=0.01)$ level of significance, \#NS-Non significant

in case of family income ( $\chi^{2}$ value 19.5$)$ and organizational membership ( $\chi^{2}$ value 6.33). Hence, it can be concluded that only family income and organizational membership are associated with level of awareness.

\section{Conclusion}

Most of the rural mothers were fully aware about their benefits under JSY scheme but less aware of other aspects of the scheme. The level of awareness of rural mothers was associated with family income and organizational membership. Various media and interventions may be used to create awareness among rural mothers. Thus, it imperative to ensure proper utilization of the JSY facilities by its beneficiaries.

\section{References}

Ade, A., Revati, S., Kulkarni, A., 2014. Reproductive health profile and health seeking behaviour among muslim women of urban slum of Raichur, Karnataka. International Journal of Research \& Health Sciences 2, $2,444-48$.

Barnagarwala, T., 2014. India has the highest number of maternal death. Retrieved from:http://indianexpress. com/articleindia-others/india-has-highest-number-ofmaternal-deaths/.

Chatterjee, S., Das, D., Singh, R., Basu, A., Chakraborty, A., Ghosh, P., 2015. Awareness about Janani Suraksha
Karyakaram among pregnant mothers-a community based study in a rural area of West Bengal, India. IOSR Journal of Dental and Medical Sciences 14, 9, 01-05.

Doetinchem, O., Xu, K., Carrin, G., 2008. Conditional cash transfers: What's in it for health. World Health Organization. Geneva, Switzerland; Retrieved from: http://www.who.int/health_financing/documents/ pb_e_08_1-cct.pdf.

Janani Suraksha Yojana: A demand driven intervention. 2008. NRHM Newsletter July-Sept.

Kaur, H., Kaur, A., Kaur, H., Devgun, P., 2015. A study of utilization of Janani Suraksha Yojana (JSY) scheme, among beneficiaries in a rural area of Punjab. National Journal of Research and Community Medicine 4, 1, 114-123.

Kaushik, A., Mishra, P.C., Kesharwani, P., Richa and Hussain, A.M., 2010. Awareness about JSY among reproductive age women in rural area of Varanasi. Indian Journal of Preventive and Social Medicine 41, 158-161.

Mandal, D., K., Kaur, P., Murhekar, M., V., BMC, 2012. Low coverage of Janani Suraksha Yojana among mothers in 24-Parganas (South) of West Bengal in 2009. In: BMC Proceedings. 6(Suppl 1), 3. Available from: http:// bmcproc.biomedcentral.com/articles/10.1186/17536561-6-S1-O3. DOI: 10.1186/1753-6561-6-S1-O3

Mishra, C.P., 2007. Critical Links in Child Survival. Editorial International Journal of Public Sector Managemen, 38, 
104-110.

Nautiyal, V., Dabral, J., 2012. Women issues in newspapers of Uttarakhand. Global Media Journal 3(1), 1-10.

Saha, U.C., Saha, K.B., 2010. A trend in women's health in India- what has been achieved and what can be done. International Electronic Journal of Rural and Remote Health Research, Education Practice and Policy 201, $1-11$.

Ray, K.S., 2014. Awareness and utilization of National Rural Health Mission services among people of selected rural areas in the state of Maharashtra. National Journal of Community Medicine 5, 387-91.

Singh, S.H., Tamulee, P., 2012. Janani Suraksha Yojana: Impact on socio-economic conditions among beneficiary families. International Journal of Scientific Research Publication 2, 1-4.

Panja, K.T., Mukhopadhyay, K.D., Sinha, N., Saren, B.A.,
Sinhababu, A., Biswas, B.A., 2016. Are institutional deliveries promoted by Janani Suraksha Yojana in a district of West Bengal, India? Indian Journal of Public Health 56, 69-72.

Sharma, P., Srivastava, K., Vyas, S., Kishore, S., Semwal, J., 2012. Is Janani Suraksha Yojana's (JSY) awareness a reflection on healthy pregnancy outcome? differences in rural areas and urban slums. National Journal of Community Medicine 2, 187-192.

Pahwa, P., Sood, A., 2013. Existing practices and barriers to access of MCH services- a case study of residential urban slums of district Mohali, Punjab, India. Global J of Medicine and Public Health 2, 1-8.

Ramniwas, Prabhu, J., 2015. A study to assess the knowledge and attitude on Janani Suraksha Yojana among family members in selected rural areas, Amroha. International Journal of Nursing Education 7, 125-30. 